\title{
Liderança feminina em contexto de economia solidária - o caso da feira agroecológica e cultural de mulheres no Butantã
}

\section{Women's leadership in the context of solidarity economy - the case of the agroecological and cultural women's fair in Butantã}

\author{
Lucyana Oliveira Barbosa ${ }^{1}$, Fabiana Pinto de Almeida Bizarria ${ }^{2}{ }^{1 *}$, Flávia Lorenne Sampaio \\ Barbosa $^{3}$, Simone Costa Guimarães ${ }^{4}$
}

\begin{abstract}
RESUMO
Objetiva-se compreender narrativas de mulheres vinculadas à Feira Agroecológica e Cultural de Mulheres no Butantã, São Paulo (SP), na perspectiva da liderança feminina comunitária e da economia solidária. Para tanto, se desenvolve estudo observacional em 08 microdocumentários produzidos em 2020 pela Aguapé Produções, em parceria com a Secretaria Municipal de Cultura de São Paulo. A Feira, desde 2017, é uma instituição sem fins lucrativos com atuação em âmbito nacional e internacional, que visa estimular, promover e fortalecer a liderança feminina, por meio de reflexões e ações baseadas em participação e valorização da economia solidária, da sustentabilidade e da coletividade. A liderança feminina, pelo estudo, envolve a definição do espaço coletivo de diálogo sobre a própria existência, em que são reconhecidas as potencialidades e as histórias familiares. A economia solidária, no que lhe concerne, se configura como espaço de luta por reconhecimento das diferenças, mas, principalmente, pelo exercício do diálogo e na atuação da gestão participativa. Por fim, além de espaço socioeconômico, a Feira favorece formação crítica, considerando maior discussão sobre papéis sociais historicamente designados à mulher.
\end{abstract}

Palavras-chave: Liderança feminina; Economia solidária; Agroecologia.

\begin{abstract}
The objective is to understand narratives of women linked to the Agroecological and Cultural Women's Fair in Butantã, São Paulo (SP), from the perspective of female community leadership and solidarity economy. To this end, an observational study is developed in 08 microdocumentaries produced in 2020 by Aguapé Productions, in partnership with the Municipal Secretariat of Culture of São Paulo. The Fair, since 2017, is a non-profit institution operating nationally and internationally, which aims to stimulate, promote, and strengthen female leadership through reflections and actions based on participation and appreciation of the solidarity economy, sustainability, and collectivity. Women's leadership, according to the study, involves the definition of the collective space for dialogue about one's own existence, in which the potentialities and family histories are recognized. The solidarity economy, as far as it is concerned, is configured as a space of struggle for the recognition of differences, but, mainly, by the exercise of dialogue and in the performance of participative management. Finally, besides being a socioeconomic space, the Fair favors critical formation, considering greater discussion about social roles historically assigned to women.
\end{abstract}

Keywords: Female leadership. Solidarity economy. Agroecology.

\footnotetext{
1,3,4 Universidade Federal do Piauí

${ }^{2}$ Faculdade Luciano Feijão e UFPI

*E-mail: fabiana.almeida.flf@gmail.com
} 


\section{INTRODUÇÃO}

No panorama mundial do século XXI, percebe-se que o complexo conceito de agroecologia, extrapola, consideravelmente, a composição por aglutinação dos termos agronomia e ecologia (CAPORAL; AZEVEDO, 2011). O uso da biotecnologia, por exemplo, como aliada às práticas agro-culturais pode representar valiosa contribuição na construção de um ambiente favorável às discussões e soluções de questões socioambientais (CAPORAL; AZEVEDO, 2011).

Agroecologia, como conceito, perpassa pelo campo dos movimentos sociais, com a democratização do acesso à terra e seus recursos naturais, fundamentados nos princípios de equidade e da justiça social, como meios de alcançar o bem-estar coletivo, a partir da visão de desenvolvimento social integral (NORDER, LAMINE, BELLON; BRANDENBURG, 2016). Considera a transformação dos meios de produção, distribuição e consumo, características das etapas de evolução e construção, baseadas nos parâmetros de desenvolvimento sustentável (WEZEL et. al., 2009), e, também reúne princípios e valores culturais tradicionais experienciados, especialmente, por famílias camponesas ou indígenas, acumulados ao longo de gerações.

No Brasil, a agroecologia tem seus primeiros registros nos anos finais de 1970, a partir de ações orquestradas por grupos e associações de trabalhadores do campo, Comunidades Eclesiais de Base (CEBS) e Organizações Não Governamentais e movimentos sociais (ONG's), distribuídos por todo o território brasileiro (MONTEIRO; LONDRES, 2017). Esse movimento é ampliado com o potencial produtivo-sustentável da agricultura familiar, e sua consequente valorização a partir da década de 1990, com base em políticas públicas destinadas aos pequenos produtores, que permitiu avançar, de forma significativa o desenvolvimento e a consolidação da agroecologia.

A participação de produtores em ações e eventos promovidos por instituições de ensino, pesquisa e extensão, estimulou a troca de saberes e incentivou a participação e o envolvimento no processo de construção e disseminação de conhecimento em agroecologia (SAMBUICHI et. al., 2017). São programas, projetos e encontros ligados à temática "agricultura alternativa", que se disseminaram pelo Brasil por meio da formação de grupos e redes agroecológicas compostos por pessoas do campo, muitas vezes, ignoradas, marginalizadas e excluídas do contexto socioeconômico-cultural regional citação. 
Como espaços destinados à produção, distribuição e comercialização de produtos orgânicos, caminho alternativo à geração de renda (CAPORAL; COSTABEBER, 2004), também se exercita o diálogo, que potencializa o redescobrir dos saberes regionais, com ampliação de sua valorização e transmissão para gerações futuras (DOWBOR, 2006). Exemplo disso, é a Articulação Nacional de Agroecologia (ANA), no ano de 2002, formada como espaço integrador de organizações e sociedade civil em atenção à promoção da agroecologia e do desenvolvimento rural sustentável por meio do fortalecimento dos movimentos e redes que atuam com a produção familiar (O que é a ANA, s.d., online). Dados de 2021 informam que a ANA reúne 23 redes estaduais e regionais e 15 movimentos sociais de âmbito nacional, bem como atua na Comissão Nacional de Agroecologia e Produção Orgânica (CNAPO), no Conselho Nacional de Segurança Alimentar e Nutricional (CONSEA) e no Conselho Nacional de Desenvolvimento Rural Sustentável (CONDRAF).

O fortalecimento da agroecologia pode, também, ser reconhecido no Brasil com a Marcha das Margaridas, movimento formado por mulheres agricultoras, marisqueiras e quilombolas, que atua em defesa do respeito aos direitos essenciais: educação, saúde e combate à violência, e, ainda, em favor da implementação de políticas públicas que visem garantir o direito à água e à terra (MOREIRA, 2019). Movimentos semelhantes agregam empreendedoras, produtoras, artesãs e artistas, formando coletivos, integrados e plurais, em apoio mútuo, que permite maior visibilidade, escoamento de produção e geração de renda.

Assim, em uma ação da Frente de Mulheres da Associação Portal RAS nasce, no ano de 2017, a Feira Agroecológica e Cultural de Mulheres no Butantã, que, em parceria com a Prefeitura do Butantã, em São Paulo (SP), passou a ocupar parte da área de preservação do parque, no Viveiro II (Feira Agroecológica e Cultural de Mulheres no Butantã, n.d., 2021, on line). Uma vez por mês, a partir de referências culturais inovadoras, a feira mobiliza a comunidade, artistas convidadas e expositoras, com influência em comportamentos de proteção ambiental, protagonismo e liderança da mulher, participação e valorização das vivências culturais e sociais (SILIPRANDI, 2015).

Pesquisas como, Singer (2005), Sambuichi et al (2017) e Caporal e Azevedo (2011), por exemplo, reforçam a importância de feiras como espaço de compartilhamento de experiências de vida e de trabalho. Também há estudos que demonstram a influência das feiras de agroecologia para o desenvolvimento de comportamentos de proteção ao meio ambiente, bem como uma melhor integração social, com respeito e valorização das 
potencialidades regionais (ALTIERI, 2002; CAPORAL; COSTABEBER, 2004; OLIVEIRA, 2005).

Observa-se, ainda, que feiras de agroecologia são espaços ocupados por muitas mulheres, produzindo e comercializando, trabalhando e gerando renda, o que pode mobilizar o desenvolvimento de protagonismos e lideranças. Dessa forma, a pesquisa objetiva compreender narrativas de mulheres vinculadas à Feira Agroecológica e Cultural de Mulheres no Butantã na perspectiva da liderança feminina comunitária e da economia solidária.

Em contexto comunitário, por sua vez, há importante reconhecimento do papel da mulher como mobilizadora de processos. Em parte, em função dos desafios da participação da mulher no mercado de trabalho formal, considerando as múltiplas atividades socialmente definidas como da mulher-mãe-esposa; e, também, em decorrência de contextos de crise, em que a mulher é requerida a contribuir com a sobrevivência, sendo, muitas vezes, a única responsável financeiramente.

A contribuição esperada envolve desvelar narrativas sobre processos despertados pela vivência da feira, ao passo que o perfil agroecológico explora as potencialidades regionais com atenção às questões ambientais. A liderança comunitária, acredita-se, dialoga com mulheres que atuam nesses espaços, reunindo outras mulheres na configuração de espaços de vida-trabalho com a garantia de renda. Assim, analisar a relação de mulheres em feiras agroecológicas, portanto, pode suscitar melhor compreensão sobre o exercício de sua atuação no âmbito desses espaços.

\section{Economia solidária e as feiras agroecológicas}

A economia solidária no Brasil ganha expressão desde os anos de 1990 (Dos Santos, 2014), em parte, em função de problemas estruturais do trabalho e de fragilidades das organizações públicas e dos programas sociais (SILVA, 2018). Como consequência do modelo capitalista, focado na maximização do lucro, a competição leva à concentração de riqueza e exclusão social (CATTANI, 2007). Dessa feita, diferente do sistema heterogestionário, hierarquizado, pautado em autoridade, empreendimentos de economia solidária atuam com igualdade de direitos, com participação equitativa e democrática, por meio do exercício da autogestão (SINGER, 2008).

Para tanto, nos últimos anos, esse modelo econômico e social tem alcançado maior relevância e significado, apresentando-se na literatura recente a partir dos princípios e valores 
inovadores, de articulação, integração, emancipação, inclusão e desenvolvimento, demonstrado por estudos como de Alves et al (2016a), Dubeux e Batista (2017), Leal e de Sá Rodrigues (2018), e da Silva, Costa e Teixeira (2020).

$\mathrm{Na}$ economia solidária, o apoio recíproco e indistinto tem como ponto prioritário a valorização do ser humano, sendo este o elemento central da geração de renda. Possibilita, assim, o resgate da autoestima, a (re)descoberta da força de trabalho, da capacidade produtiva e de autonomia financeira e, ainda, do sentimento de pertencimento a um grupo ou lugar, tendo como princípios essenciais a solidariedade, a cooperação, o respeito para com o meio ambiente, o consumo consciente e sustentável (ALTIERI, 2002), a valorização do bem-estar social, do comércio justo e da autogestão. Nesse ponto, os trabalhadores, em autogestão, se reúnem em grupos cooperados ou por associação, promovem auto-aprendizado, possibilitando a relação do conhecimento com a prática de maneira coletiva, conseguindo, assim, eficiência em empreendimentos pautados por princípios solidários (GAIGER, 2013).

Em expansão no Brasil, a economia solidária reúne, em sua maioria, micro ou pequenas empresas (SINGER, 2008), o que implica em uma receita anual de até 4,8 milhões de reais (definido na Lei Geral das Micro e Pequenas Empresas - Lei Complementar $n^{\circ}$ 123/2006), por cada empreendimento solidário, movimentando, anualmente, em torno de 12 bilhões de reais, conforme noticiado pela Rede Brasil Atual (Economia. Rede Brasil AtualRBA, n.d., 2019, online), a partir de dados divulgados pela Agenda Institucional do Cooperativismo em julho de 2019.

Segundo o IBGE, conforme dados do Censo Agropecuário realizado em 2017, a quantidade de empreendimentos rurais no país ultrapassou a marca de 5 milhões, registrando aumento de quase 6\% no período compreendido entre 2006 e 2016, totalizando 5.073.324 unidades rurais e ocupando $41 \%$ da área total do nosso território. Crescimento, também, observado no mercado empreendedor, com um aumento de quase 300\% no número de novas unidades orgânicas cadastradas junto ao Ministério da Agricultura, Pecuária e Abastecimento (MAPA), no período de 2010 a 2018, contabilizando, ao final do ano de 2019, cerca de 22 mil unidades de produção orgânica regulares cadastradas (Coordenação Geral de Comunicação Social; Mapa; Brito, s.d., on line).

Apesar do contexto de crise econômica nos últimos anos e de saúde pública vivenciada em 2020, como informa a notícia publicada pela Associação Brasileira de Supermercados, o segmento teve alta de 30\% nas vendas no ano de 2020 (ABRAS, n.d., 
2021, online), com importante aumento do consumo de produtos orgânicos, como informa Cobi Cruz, diretor da Associação de Promoção dos Orgânicos (Organis, n.d, on line). Ainda, importantes reformulações da Política Nacional de Alimentação Escolar (PNAE), assegurada desde a Constituição de 1988, contou com avanços em 2015, com a publicação da Resolução CD/FNDE $n^{\circ} 4$ (BRASIL, 2015), que estimulou a agricultura familiar e incentivou a produção de orgânicos, priorizando, ainda, a aquisição desses produtos pelo ente público, destinando-o à merenda escolar.

As feiras agroecológicas, portanto, surgem a partir da necessidade de organização e construção de um caminho alternativo de geração de renda (LIMA et al, 2018), numa perspectiva menos formal, com enfoque na cooperação e na coletividade, logo, mais democrático, plural e conscientemente atuante na construção de um espaço de trabalho sustentável, o qual possibilita a troca de experiências e saberes (DAVI et al, 2020), associada à produção, venda e consumo de produtos artesanais e alimentação saudável, mantendo-se a qualidade e reduzindo-se os custos, dispensando os eventuais atravessadores, passando, assim, a percorrer um caminho mais curto, diretamente do produtor para o consumidor (LEITE et al, 2020).

Nesse mesmo cenário, observou-se a crescente presença e positiva atuação feminina, antes restrita aos "bastidores". A mulher passou a perceber o espaço das feiras agroecológicas como oportunidade de resistência, aprendizagem e busca da autonomia financeira (GRIMM; OLIVEIRA, 2019; BONA; MAY, 2019), identificando as fragilidades, exercitando e compartilhando as habilidades, bem como, assumindo papéis de protagonismo e liderança (CRUZ, LIMA; CAMPOS, 2020). Destacando-se nas novas funções assumidas, a consistente atuação, proporcionada pelo empoderamento feminino (GOMEZ, DE LUCENA, CRISTINA, 2016) tem influenciado fortemente a atual predominância da mulher nos respectivos espaços, como assevera Almeida (2020).

\section{Liderança feminina e a economia solidária}

A liderança como objeto de investigação, no Brasil, tem evolução a partir dos anos de 1990 (FONSECA, PORTO; BORGES-ANDRADE, 2015). Historicamente, é representada como função naturalmente ocupada por homens (EAGLY, 2007). Hryniewicz e Vianna (2018), por exemplo, demostram resistência à promoção e ocupação de cargos de liderança por mulheres, bem como registram a desigualdade dos salários, conforme o gênero. $\mathrm{O}$ que 
converge em obstáculos à mulher em relação ao espaço da liderança, em defesa do lugar a ser assumido por ela junto ao cuidado familiar e atividades domésticas (EAGLY; CARLI, 2007).

O exercício de liderança feminina, portanto, destaca a capacidade das mulheres de mobilizar, reunir, bem como alcança níveis exitosos de resultados e eficácia (EAGLY, 2007b), particularmente, em relação ao reconhecimento da necessidade de mudanças em relação à divisão social do trabalho baseado em gênero, o que favorece novas leituras sobre compartilhamento do poder em sociedade ainda inspirada em cultura patriarcal (Machado, 2002).

Em torno desse processo de empoderamento, no Brasil, têm-se o desafio da feminização da pobreza, como ressaltam Novellino (2004), Costa, Pinheiro, Medeiros e Queiroz (2005), Castro (2001), Macedo (2008), e Alves e Silva (2015). Mesmo com a ampliação da população feminina no mercado de trabalho, em contexto de transformação cultural, econômica e social em curso, persiste a desigualdade nas relações de trabalho (GUÉRIN, 2003; BIROLI, 2018; BEZERRA et al, 2019).

As atividades exercidas no âmbito familiar, como, por exemplo, o cuidado doméstico e dos filhos não são percebidas como trabalho formal, permanecendo invisíveis e desvalorizadas, como detalha Woitowicz (2008), em referência à Michele Perrot. No âmbito do trabalho no campo, por outro lado, o processo de "modernização conservadora", como detalha Silva (1981), revela desvantagem feminina em relação ao predomínio do poder decisório masculino, quando as mulheres se distanciaram ainda mais dos afazeres agrícolas, simultaneamente, à incorporação tecnológica desencadeada pela Revolução Verde. Dessa forma, a mulher passou a participar, compreender e decidir cada vez menos nos processos de cultivo, produção e escoamento da colheita, restringindo seus afazeres às atividades domésticas e cuidados da família (BRUMER, 2004).

Impulsionado pelos novos caminhos e oportunidades assimiladas pelos movimentos da agricultura alternativa, tornou-se premente a necessidade de aliar o conhecimento empírico e ancestral das populações campesinas, aos saberes técnicos e acadêmicos (BRANDERBURG, 2002), promovendo a integração de projetos sociais e projetos científicos (WEZEL, et al, 2009), visando a geração de renda e viabilizando a autonomia financeira, reunidos pelos preceitos da agroecologia. Com esses projetos são oportunizados espaços de valorização do protagonismo feminino, em que o equilíbrio e a ética também assumem papel relevante, como base fundamental dessas relações (SILIPRANDI, 2009). 
Tal cenário converge com a janela de oportunidades relacionada ao empreendedorismo solidário (MUÑOZ; KIBLER, 2016), considerando seus valores de reciprocidade, em que as experiências são partilhadas com maior possibilidade de inclusão (SINGER, 2005), ampliando a participação, essencial ao empoderamento. Assim, a participação das mulheres nesses empreendimentos ressalta, ainda, a necessidade de conciliação da vida familiar e profissional, com menos acesso às oportunidades de crédito e propriedade, destacando-se, como espaço prioritário de atuação feminina, as áreas de alimentação, costura e manutenção de roupas, saúde, serviços de tratamento, educação e formação (GUÉRIN, 2005).

Em espaço solidário, há possibilidade de enfrentamento da subalternidade feminina socialmente cristalizada (OLIVEIRA, 2020; BEZERRA, 2018), a desconstrução do individualismo, aliada à construção coletiva e ao comprometimento para com os outros, com exercício da autonomia e do fortalecimento das redes de cooperação (ESTEVAM et al, 2013). Observa-se que nesse espaço, a mulher se faz mais presente e integrada, considerando os valores que induz ao fortalecimento dos vínculos, com maior integração e inclusão (OLIVEIRA, 2005).

A economia solidária como espaço de politização (CORTIZO; OLIVEIRA, 2004), portanto, intensifica a capacidade de expansão da participação de seus integrantes em outros espaços públicos de decisão, ao passo que habilita ao desenvolvimento do enfretamento conjunto dos desafios e da formulação de propostas e alternativas viáveis de solução (OLIVEIRA, 2005). Dessa forma, representam, para Asseburg e Gaiger (2007), eficazes ferramentas de combate à pobreza e redução de marginalização e desigualdades sociais, considerando o desenvolvimento de habilidades de agir, de participar e de decidir.

Em movimento associativo, os saberes se reúnem em prol da superação de desafios coletivos, como, por exemplo, a marginalização social e a discriminação relacionada ao gênero (ANDRIOLI, 2002; LAGARDE, 2018). Ante a experiência feminina, a economia solidária, ainda, auxilia em movimentos da "supremacia dos homens" e da subalternidade socialmente imposta à mulher, ao longo das gerações (OLIVEIRA, 2005).

Assim, refletir sobre a liderança em contextos de economia solidária, registra a importância indissociável do papel da justiça, do espaço de discussão, reflexão e deliberação, além da (re)definição e (re)valorização, face a luta pela redução de desigualdade intrafamiliar, que possibilitam a coexistência pacífica no cotidiano de atividades profissional e familiar, 
podendo gerar resultados positivos mais expressivos, abrangentes e duradouros na (re)construção da igualdade social e de gênero (GUÉRIN, 2005).

Nesse sentido, experiências de liderança da mulher no âmbito comunitário, em economia solidária, têm ampliado possibilidades para a melhoria da autoestima, e autoconfiança, com a possibilidade de construção de novas relações sociais, empoderando, gerando renda e possibilitando a conquista da independência financeira (BEZERRA et al, 2019). Nesses espaços, há fortalecimento das mulheres, em exercício da empatia e da sororidade, valorizando o bem social coletivo, bem como direitos, talentos e habilidades, que podem reverberar em resistência à cultura machista, com impacto positivo na conquista de espaço pelo gênero feminino (NASCIMENTO SILVA, 2020).

\section{METODOLOGIA}

A pesquisa desenvolve levantamento bibliográfico e documental (GIL, 2008), por meio de arquivos de áudio e vídeo, identificando conceitos, valores e princípios norteadores, históricos e atuais, relacionados à agroecologia, economia solidária e liderança feminina, com suporte no caso da Feira Agroecológica e Cultura de Mulheres no Butantã, desenvolvida na cidade de São Paulo (SP).

Em relação à feira, foram identificados 08 microdocumentários (Quadro 1), disponíveis na internet, por meio da plataforma YouTube, site de compartilhamento de vídeos. As mídias foram produzidas no ano de 2020, pela Aguapé Produções, através do Edital (Edital n 06/2019/SMC/SMC-NFFC) de Apoio à Criação Artística - Linguagem Reggae, em parceria com a Secretaria Municipal de Cultura e Prefeitura Municipal de São Paulo.

A utilização dos vídeos possibilitou o registro da experiência da Feira Agroecológica no Butantã, bem como representações associadas à temática da economia solidária e liderança feminina, em função dos desafios, conquistas dos atores narradas sobre o projeto. Cada microdocumentário possui entre 3 e 5 minutos, sendo que cada vídeo possui denominação específica, abordando a temática central discutida, conforme quadro 1. 
Quadro 1 - Microdocumentários Projeto "Força Feminina: a Feira Agroecológica e Cultural de Mulheres no Butantã".

\begin{tabular}{|c|c|c|c|}
\hline $\begin{array}{c}\text { Vúdeo 1 } \\
\text { Mulheres na Autogestão } \\
\text { do Território }\end{array}$ & $\begin{array}{c}\text { Vídeo 2 } \\
\text { Economia Solidária } \\
3: 20^{\prime}\end{array}$ & $\begin{array}{c}\text { Vídeo 3 } \\
\text { Ancestralidade e Memória } \\
\text { Matriarcal Africana } \\
5: 06,\end{array}$ & $\begin{array}{c}\text { Vídeo 4 } \\
\text { Economia Feminista } \\
4: 12^{\prime},\end{array}$ \\
\hline $\begin{array}{c}\text { Vídeo 5 } \\
\text { Agroecologia e o Eu Vital } \\
4: 38^{\prime},\end{array}$ & $\begin{array}{c}\text { Mulheres Artistas e } \\
\text { a Cultura Reggae } \\
3: 17,\end{array}$ & $\begin{array}{c}\text { Vódeo 7 } \\
\text { Complementaridade Alpha e } \\
\text { Ômega } \\
4: 37,\end{array}$ & $\begin{array}{c}\text { Forḉdeo 8 Feminina } \\
4: 50,\end{array}$ \\
\hline
\end{tabular}

Fonte: Microdocumentários da Série "Força Feminina: a Feira Agroecológica e Cultural de Mulheres no Butantã” - Aguapé Produções. Ano 2020.

Disponíveis no Youtube (https://www.youtube.com/c/aguapeproducoes)

Em análise prévia dos vídeos, observa-se a individualidade de cada narrativa, posto que cada microdocumentário possui tema específico, embora o contexto geral abordado seja relacionado a experiência da mulher junto à Feira. Considerando a relevância temática às abordagens individualizadas de questões pertinentes, cada vídeo proporciona observações ampliadas do espectador com a experiência, sendo fundamental para análises que consideram realização de pesquisa por meio de estudo observacional (TAMES, 2014).

Compreendendo a importância e a presença cada vez maior das imagens em nosso dia a dia, as quais registram e refletem as circunstâncias e os momentos históricos e sociais vivenciados, Flick (2004), citando Dezin (1989), propõe um modelo de análise dos dados audiovisuais, composto por quatro passos: (i) inicia-se com a anotação das impressões, questões e padrões considerados principais, analisando o registro do filme de modo amplo; (ii) anota-se as cenas-chave e formula-se as questões de pesquisa; (iii) procede-se às "microanálises estruturadas" das cenas; (iv) por fim, passa-se à leitura (realidade e subversiva) do filme, respondendo à questão de pesquisa formulada, redigindo-se a interpretação final.

No processo de transcrição dos microdocumentários, foi preservado a identidade das narradoras/entrevistadas, substituindo os respectivos nomes pelas letras iniciais, acompanhadas da função/projeto ou entidade que representam, além de segmentos selecionados dessas narrativas e das principais ideias capturadas (temas), detalhadas no quadro 2.

Quanto à análise temática (BARDIN, 2016) aplicada ao objeto desta pesquisa, procedeu-se às ações de recorte do texto, em unidades de categorias comparáveis e 
codificação de registro de dados, "centrada no sujeito" abordado pelo discurso de temas, de modo que os elementos de significação puderam ser detectados, descontados e classificados, bem como, orientados e delimitados pela dimensão da análise em face do objetivo pretendido, como proposto por Bardin (2016).

\section{O caso da feira agroecológica e cultural de mulheres no butantã}

A Feira Agroecológica e Cultural de Mulheres no Butantã, desde 2017, é gerida por um grupo de mulheres produtoras, com a perspectiva da economia solidária, considerando o princípio da rede solidária (SINGER, 2002). A feira, em estudo, configura-se como espaço aprazível, democrático e coletivo, com foco no trabalho artesanal, na agricultura familiar orgânica e sustentável e na oportunidade de geração de renda, fundamentada no protagonismo empreendedor feminino, na diversidade e na inclusão social, em consonância aos princípios da economia solidária (SILIPRANDI, 2015; ALVES, 2016).

A feira, em modelo de gestão coletiva, reúne a Rede de Economia Solidária e

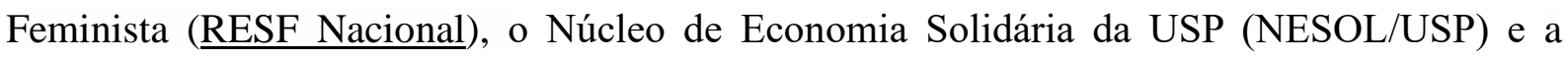
Incubadora Tecnológica de Cooperativas Populares da USP (ITCP/USP), co-organizado pela Frente de Mulheres, grupo derivado da Associação Nacional do Reggae, uma instituição sem fins lucrativos que congrega em âmbito nacional e internacional, que visa estimular, promover e fortalecer a liderança feminina, por meio de reflexões e ações baseadas em participação e valorização da economia solidária, da sustentabilidade e da coletividade (Feira Agroecológica e Cultura de Mulheres no Butantã, n.d., 2021, on line).

A feira ocorre de forma mensal, aos finais de semana, com acesso gratuito ao público e conta com apoio da Prefeitura Regional do Butantã. Em espaço, com árvores, gramado e animais, ocorre a exposição e a venda de produtos naturais, artesanato, alimentação saudável e de qualidade, diretamente do produtor para o consumidor, sem pesticida e sem atravessadores. Além disso, ocorrem palestras, oficinas e rodas de conversa, bem como contação de história, capoeira, yoga, dança e música. Cada evento da feira, reúne 40 a 50 expositoras, em geral produtoras selecionadas previamente pelo projeto. Há recolhimento de $10 \%$ sobre o valor final arrecadado, destinado ao fundo coletivo do grupo para manutenção da feira (OLIVEIRA, 2019, online). 


\section{Análise das narrativas}

A análise das narrativas considera as organizadoras, convidadas, apoiadoras e expositoras da feira, entrevistadas ao longo das gravações dos microdocumentários, considerando discursos heterogêneos em variadas temáticas, sob a lente da liderança feminina em contexto de economia solidária. Para tanto, a diversidade se entrelaça nos segmentos de narrativas, o que permite a reconstrução de histórias com variadas possibilidades de encadeamentos e interpretações, mantendo-se, no entanto, o elemento retrospectivo próprio dessa metodologia.

Nesse sentido, realizou-se a transcrição e seleção das principais ideias em segmentos narrados pelas participantes, conforme quadro 2. Com base nesses trechos, procedeu-se, em seguida, à discussão dos resultados. 
Quadro 2 - Trechos das entrevistas apresentadas nos Microdocumentários da Série "Força Feminina: a Feira Agroecológica e Cultural de Mulheres no Butantã".

Título 01 - Mulheres na Autogestão do Território (https://www.youtube.com/watch?v=y2wqnA5pTCw)

\begin{tabular}{|c|c|c|c|}
\hline Identificação & $\begin{array}{l}\text { Função no Projeto ou } \\
\text { entidade/grupo que } \\
\text { representa }\end{array}$ & Temas & Segmentos de Narrativa \\
\hline F. G. & $\begin{array}{l}\text { Coordenação da Feira } \\
\text { Agroecológica e Cultural } \\
\text { no Butantã (2018-2019) }\end{array}$ & $\begin{array}{l}\text { Agroecologia; } \\
\text { Economia solidária; } \\
\text { Luta por direitos; } \\
\text { Frente feminista }\end{array}$ & $\begin{array}{l}\text { Mulheres estão a todo momento, também, se fortalecendo, mas quando a gente tá só entre mulheres acho que } \\
\text { isso fica mais potente [...]. E como dois principais, assim, princípios, né, valores que a gente teve lá desde o } \\
\text { começo é a questão da agroecologia e economia solidária[...] Com certeza, também, é um espaço de lutas por } \\
\text { direitos[...] A feira não se auto denomina uma feira feminista, mas a gente tem se entendido, cada vez mais, } \\
\text { atuando numa frente feminista. }\end{array}$ \\
\hline A. L. L. & $\begin{array}{l}\text { Coordenação da Feira } \\
\text { Agroecológica e Cultural } \\
\text { no Butantã (2018-2019) }\end{array}$ & $\begin{array}{l}\text { Reprodução da vida; } \\
\text { Cuidado materno / } \\
\text { familiar; } \\
\text { Divisão de trabalho } \\
\text { (por gênero); } \\
\text { Oportunidade }\end{array}$ & $\begin{array}{l}\text { E eu vejo as mulheres que “tão" conseguindo com as suas famílias, com os seus companheiros, dividir o } \\
\text { trabalho de reprodução da vida, também permite que a gente vá criando esse repertório, de como é que é um } \\
\text { espaço em que a gente dá conta do cuidado[...] }\end{array}$ \\
\hline
\end{tabular}

Título 02 - Economia Solidária (https://www.youtube.com/watch?v=XlQx93mFbPE)

\begin{tabular}{|c|c|c|c|}
\hline F. G. & $\begin{array}{l}\text { Coordenação da Feira } \\
\text { Agroecológica e Cultural } \\
\text { no Butantã (2018-2019) }\end{array}$ & $\begin{array}{l}\text { Pertencimento; } \\
\text { Construção coletiva; } \\
\text { Gestão Participativa }\end{array}$ & $\begin{array}{l}\text { Ter um cuidado para que a gente[...]todas se sintam parte, né, então, se tornar mesmo um espaço coletivo, de } \\
\text { construção coletiva[...] Construção dos acordos, construção do espaço, construção dos princípios.[...] }\end{array}$ \\
\hline E. S. & $\begin{array}{l}\text { Associação das Mulheres } \\
\text { da Economia Solidária } \\
\text { (AMESOL)/ Tendarte } \\
\text { Artesanato }\end{array}$ & $\begin{array}{l}\text { Autogestão; } \\
\text { Economia solidária; } \\
\text { Coletividade; } \\
\text { Educação/formação }\end{array}$ & $\begin{array}{l}\text { [...] a gente tá falando de auto-gestão, que é o princípio principal da economia solidária, que até para organizar } \\
\text { esse espaço, esse pessoal vem junto e colabora, é uma coisa de fazer junto, coletivamente, que também é uma } \\
\text { característica da economia solidária[...]Não é uma feira só para comercializar, é uma feira também com recorte } \\
\text { de educação, de formação "pras" mulheres! }\end{array}$ \\
\hline
\end{tabular}

Título 03 - Ancestralidade e Memória Matriarcal Africana (https://www.youtube.com/watch?v= 7tk13LHVil)

\begin{tabular}{|c|c|c|c|}
\hline A. R. & Brincante/cantante da & Valorizar raízes & Eu entendo que no meu passado existe algo potente, poderoso e o meu futuro, pode ser assim também[...] \\
\hline
\end{tabular}




\begin{tabular}{|c|c|c|c|}
\hline & $\begin{array}{l}\text { cultura popular, } \\
\text { Bloco/grupo vocal Ilú } \\
\text { Obá de Min }\end{array}$ & culturais & \\
\hline R. C. & $\begin{array}{l}\text { Cantora e compositora } \\
\text { Dawtas of Aya }\end{array}$ & $\begin{array}{l}\text { Fortalecer/empoderar } \\
\text { a mulher; } \\
\text { Ancestralidade; }\end{array}$ & $\begin{array}{l}\text { Cada mulher, ela tem a sua força, ela tem a sua ancestralidade dentro, muitas vezes, inaflorada[...] } \\
\text { Empoderar quem "tá" perto da gente é muito[...] é muito melhor, é muito mais fácil[...] }\end{array}$ \\
\hline
\end{tabular}

Título 04 - Economia Feminista (https://www.youtube.com/watch?v=V3KravEMVPI)

\begin{tabular}{|c|c|c|c|}
\hline N. A. & $\begin{array}{l}\text { Coletivo Kandakes Kush } \\
\text { / Almaquimia }\end{array}$ & $\begin{array}{l}\text { Afazeres domésticos; } \\
\text { Família; } \\
\text { Bem-estar }\end{array}$ & $\begin{array}{l}\text { A maioria dos homens chegam em casa e tem tudo pronto: a casa tá limpa, a roupa tá lavada, porque tem lá } \\
\text { atrás uma mulher dando condição, seja a mãe, seja companheira, seja irmã, seja família, tia [...]parece simples, } \\
\text { mas isso dá condição de bem-estar[...] é uma lógica favorável, pra que ele simplesmente trabalhe, para que ele } \\
\text { simplesmente estude! }\end{array}$ \\
\hline E. S. & $\begin{array}{l}\text { Associação das Mulheres } \\
\text { da Economia Solidária } \\
\text { (AMESOL)/ Tendarte } \\
\text { Artesanato }\end{array}$ & $\begin{array}{l}\text { Família; } \\
\text { Extensa jornada } \\
\text { feminina; } \\
\text { Produzir e escoar }\end{array}$ & $\begin{array}{l}\text { Além das dificuldades de encontrar um mercado pra escoar os produtos, as dificuldades da própria produção, de } \\
\text { você se dedicar à produção, quando você tem, além da produção, você tem uma casa, você tem uma família pra } \\
\text { cuidar[...] }\end{array}$ \\
\hline R. T. & $\begin{array}{l}\text { Pimenta artesanal e Santa } \\
\text { Regina }\end{array}$ & $\begin{array}{l}\text { Desigualdade de } \\
\text { gênero; } \\
\text { Luta por direitos }\end{array}$ & $\begin{array}{l}\text { O dia tem } 24 \text { horas, para homem e para mulher, nós pagamos os mesmos tributos e ainda temos a extensão da } \\
\text { nossa carga horária[...] eu acho que já tem mudança[...] as mulheres nem votavam, mais atrás, não muito longe, } \\
\text { as mulheres não tinham direito de ler e escrever, então eu acho que nós já avançamos bastante, tanto que hoje } \\
\text { elas são as mantenedoras, inclusive dos lares[...] Nós temos todas as obrigações dos homens, então, agora, nós } \\
\text { estamos atrás dos nossos direitos! }\end{array}$ \\
\hline
\end{tabular}

Título 05 - Agroecologia e o Eu Vital (https://www.youtube.com/watch?v=rNB8mfBdu08)

\begin{tabular}{|c|c|c|c|}
\hline M. A. & $\begin{array}{l}\text { Agricultora / Comuna da } \\
\text { Terra Irmã Alberta/MST }\end{array}$ & $\begin{array}{l}\text { Agroecologia; } \\
\text { Alimento saudável; } \\
\text { Envolvimento } \\
\text { familiar }\end{array}$ & $\begin{array}{l}\text { A gente vai trazendo e vai dizendo da importância, da gente ir melhorando a saúde, através da agroecologia, } \\
\text { produção de alimentação saudável[...] A gente precisa trabalhar a família, como conjunto, por isso que a } \\
\text { agroecologia ela é super importante, porque todos da família se envolvem com esse movimento que é trabalhar } \\
\text { a diversidade de cultura e respeito à vida, ali, né, então a mulher é importantíssima... }\end{array}$ \\
\hline J. M. & $\begin{array}{l}\text { Agrofloresteira e } \\
\text { coletora de Juçara / Yaye } \\
\text { Cosméticos Naturais }\end{array}$ & $\begin{array}{l}\text { Agrofloresta; } \\
\text { Vivência e } \\
\text { conhecimento } \\
\text { científico; } \\
\text { Geração de renda }\end{array}$ & $\begin{array}{l}\text { Que as mulheres, elas tem até um pouco mais de visão assim, do alimento da família, assim, sabe? } \\
\text { [...] A agrofloresta é na verdade uma tecnologia desenvolvida pelos índios... há centenas, milhares de anos[...] é } \\
\text { a mesma lógica, né, agroflorestal é a mesma lógica que é trabalhar em harmonia: agricultura e a floresta, né, só } \\
\text { que agora com um pouco mais de embasamento científico, técnico, assim né? Até para poder ter um retorno } \\
\text { financeiro[...] }\end{array}$ \\
\hline
\end{tabular}


Título 06 - Mulheres Artistas e a Cultura Reggae (https://www.youtube.com/watch?v=0e3w0ABIY74)

\begin{tabular}{|c|c|c|c|}
\hline R. C. & $\begin{array}{l}\text { Cantora e compositora } \\
\text { Dawtas of Aya }\end{array}$ & $\begin{array}{l}\text { Força feminina; } \\
\text { Diálogo; } \\
\text { União }\end{array}$ & $\begin{array}{l}{[\ldots] \text { nós somos fortes, nós somos valentes, nós somos determinados[...] independente de eu ser preta, de você }} \\
\text { ser branca, que a gente possa unir essas forças e dialogar, fazer um diálogo entre nós e rever essas coisas todas } \\
\text { que nos cercam [...] }\end{array}$ \\
\hline C. A. & $\begin{array}{l}\text { Professora, pedagoga, } \\
\text { dub poetry Dawtas of } \\
\text { Aya }\end{array}$ & $\begin{array}{l}\text { Reconhecer as } \\
\text { potencialidades; } \\
\text { Integração }\end{array}$ & $\begin{array}{l}\text { A gente ainda "tá" muito fechada[...] a gente ainda "tá" naquela situação de abrir, de olhar pro sol, pra poder } \\
\text { aflorar e passar pras nossas }[\ldots . .]\end{array}$ \\
\hline S. P. L. & $\begin{array}{l}\text { Professora e mãe de três } \\
\text { filhos / Jah Queen Ital } \\
\text { Food }\end{array}$ & $\begin{array}{l}\text { Oportunidade } \\
\text { feminina; } \\
\text { Compartilhar }\end{array}$ & $\begin{array}{l}{[\ldots] \text { essa visibilidade pra mulher... que ela sempre guardou dentro dela, sabe? Dá coragem pra gente também, de }} \\
\text { compartilhar boas palavras e boas meditações com outras mulheres[...] }\end{array}$ \\
\hline \multicolumn{4}{|c|}{ Título 07 - Complementariedade Alpha e Ômega (https://www.youtube.com/watch?v=0FwebVYxD8w\&t=45s) } \\
\hline C. A. & $\begin{array}{l}\text { Professora, pedagoga, } \\
\text { dub poetry Dawtas of } \\
\text { Aya }\end{array}$ & $\begin{array}{l}\text { Mulher cuidadora; } \\
\text { Reprodução da } \\
\text { divisão social de } \\
\text { gênero; } \\
\text { Sabedoria feminina } \\
\text { (matriacardo) }\end{array}$ & $\begin{array}{l}\text { [...]fui começando a entender e buscar essa perspectiva de equilíbrio, sempre observando e vendo que a mulher } \\
\text { caminha ao lado do homem, trazendo o equilíbrio, a sabedoria[...] essa sabedoria das matriarcas, das nossas } \\
\text { avós, das nossas mães, das nossas tias, as pessoas mais... mais velhas que nós[...] }\end{array}$ \\
\hline E. S. & $\begin{array}{l}\text { Associação das Mulheres } \\
\text { da Economia Solidária } \\
\text { (AMESOL)/ Tendarte } \\
\text { Artesanato }\end{array}$ & $\begin{array}{l}\text { Educação/Formação } \\
\text { (novos conceitos de } \\
\text { integração familiar) }\end{array}$ & $\begin{array}{l}\text { Não é só formar as mulheres, mas é formar os homens também, para eles entenderem isso, senão o que a gente } \\
\text { vai fazer é mandar uma pessoa para casa que vai ficar debatendo com o marido o tempo todo...ela dizendo uma } \\
\text { coisa e ele "desdizendo" o que ela "tá" dizendo...então, a gente tem que pensar na formação, acho que não tem } \\
\text { outra forma ...é a formação de ambos! }\end{array}$ \\
\hline N. A. & $\begin{array}{l}\text { Coletivo Kandakes Kush } \\
\text { / Almaquimia }\end{array}$ & $\begin{array}{l}\text { Liderança feminina; } \\
\text { Força e Coragem; } \\
\text { Oportunidade; } \\
\text { Matriarcado; } \\
\text { Concepção das } \\
\text { diferenças }\end{array}$ & $\begin{array}{l}\text { Hoje em dia eu entendo porque a coordenação tem que ser mesmo só de mulher...eu acho que é preciso até pra } \\
\text { gente identificar nossa força, sabe? [...] a gente tem como referência o matriarcado, onde a questão da mulher e } \\
\text { da força que ela tem, também com a sua fertilidade, mas não só nisso, é uma força motriz na nação... }\end{array}$ \\
\hline
\end{tabular}


Título 08 - Força Feminina (https://www.youtube.com/watch?v=0FwebVYxD8w)

\begin{tabular}{|c|c|c|c|}
\hline F. G & $\begin{array}{l}\text { Coordenação da Feira } \\
\text { Agroecológica e Cultural } \\
\text { no Butantã (2018-2019) }\end{array}$ & $\begin{array}{l}\text { Trabalho e renda } \\
\text { integrados com o } \\
\text { projeto de vida- } \\
\text { trabalho }\end{array}$ & [...] eu sinto que, pra além da questão das nossas produções e comercializações, é uma troca para a vida... \\
\hline R. C. & $\begin{array}{l}\text { Cantora e compositora } \\
\text { Dawtas of Aya }\end{array}$ & $\begin{array}{l}\text { Economia solidária; } \\
\text { Agroecologia; } \\
\text { Interação homem- } \\
\text { natureza }\end{array}$ & $\begin{array}{l}\text { É uma forma de você também "tá" em comunhão com o ambiente aqui onde você vive, seu bairro, conhecer } \\
\text { melhor as pessoas...se unir, conversar entre si, fazer uma feira...é incrível... }\end{array}$ \\
\hline S. P. L. & $\begin{array}{l}\text { Professora e mãe de três } \\
\text { filhos / Jah Queen Ital } \\
\text { Food }\end{array}$ & $\begin{array}{l}\text { Empoderamento } \\
\text { feminino }\end{array}$ & ...esse fortalecimento, que a feira nos traz pra gente poder seguir mão com mão, força com força... \\
\hline E. $S$. & $\begin{array}{l}\text { Associação das Mulheres } \\
\text { da Economia Solidária } \\
\text { (AMESOL)/ Tendarte } \\
\text { Artesanato }\end{array}$ & $\begin{array}{l}\text { Economia solidária; } \\
\text { Economia feminista }\end{array}$ & ...venham se aproximar da economia solidária, que os homens venham a conhecer a economia feminista... \\
\hline C. A. & $\begin{array}{l}\text { Professora, pedagoga, } \\
\text { dub poetry Dawtas of } \\
\text { Aya }\end{array}$ & $\begin{array}{l}\text { Desafios; } \\
\text { Sustentabilidade }\end{array}$ & $\begin{array}{l}\text { A vida tem vários desafios pra gente...estar aqui também, é muito importante, eu recomendaria pra todo mundo } \\
\text { vir, ter mais movimento desse, toda semana e continuar essa sustentabilidade... }\end{array}$ \\
\hline A. $\mathrm{R}$. & $\begin{array}{l}\text { Brincante e cantante da } \\
\text { cultura popular, Bloco e } \\
\text { grupo vocal Ilú Obá de } \\
\text { Min }\end{array}$ & $\begin{array}{l}\text { Potencial feminino; } \\
\text { Voz, poder, lugar; } \\
\text { Pensamento } \\
\text { igualitário }\end{array}$ & $\begin{array}{l}\text { A feira é incrível, porque mostra... o quão potente é o feminino, então, é importante que a gente sempre } \\
\text { lembre... dar voz, dar poder, dar um lugar pra gente expor as nossas criações... as mulheres...não é nada de } \\
\text { "diferentão... é uma forma da gente pensar de forma igualitária e ver que a potência da mulher está aí... } \\
\text { Estejamos abertos pra isso! }\end{array}$ \\
\hline
\end{tabular}




\section{DISCUSSÃO DE RESULTADOS}

No sentido da análise temática, observa-se ênfase sobre a abordagem da luta por direitos, considerando ser a feira um espaço de expressão da mulher, com exercício do empoderamento feminino por meio do trabalho e da renda (SILIPRANDI, 2015, BIROLI, 2018; BEZERRA et al, 2019). A liderança feminina, nesse caso, envolve a definição do espaço coletivo de diálogo sobre a própria existência, em que são reconhecidas as potencialidades e as histórias familiares (OLIVEIRA, 2005; BRANDENBURG, 2002), resgatando saberes e valores culturais ancestrais.

A economia solidária, nesse caso, se configura como espaço de luta por reconhecimento das diferenças (GRIMM; OLIVEIRA, 2019), mas, principalmente, pelo exercício do diálogo e na atuação da gestão participativa em que, no caso da Feira, permite as mulheres construírem seus espaços no mundo, questionando as configurações sociais e históricas que atravessam a mulher pelo predomínio da figura do homem, como detentor natural do poder decisório familiar (NASCIMENTO SILVA, 2020).

O espaço, conforme documentários, reforça os ideais de sustentabilidade e respeito aos princípios democráticos (LIMA et al, 2018), com oportunidades isonômicas e igualitárias (SINGER, 2008), no qual a mulher assume o papel de protagonismo (GOMEZ, DE LUCENA, CRISTINA, 2016), de liderança feminina (JESUS CRUZ, OLIVEIRA LIMA, CAMPOS, 2020), associando o empoderamento ao fortalecimento da autoestima (OLIVEIRA, 2005), reafirmando a capacidade de ouvir, falar, ser e fazer, independentemente do gênero e da sua condição financeira (de autonomia ou de dependência) inicial. Esse empoderamento reflete a dimensão política (CORTIZO; OLIVEIRA, 2004), ao passo que a expressão representada configura poder decisório sobre a feira e diálogos sobre a própria existência (OLIVEIRA, 2005).

A feira, ainda, é concebida pelas narrativas como espaço de formação, em que a (re)descoberta da educação e as possibilidades de mudanças associadas, ampliam a percepção sobre alternativas econômicas e de vida em sociedade (CAPORAL; COSTABEBER, 2004; DOWBOR, 2006).

A agroecologia, com suporte em economia solidária, ainda, converge com a assimilação de novos conceitos de integração familiar, com reorganização de tarefas 
familiares e os cuidados do lar (GUÉRIN, 2005), o que favorece maior discussão sobre papeis sociais historicamente designados à mulher, com possibilidades de transformação de condições de subalternidade feminina em relação à superioridade do homem (BEZERRA, 2018; OLIVEIRA, 2020; NASCIMENTO SILVA, 2020).

\section{CONSIDERAÇÕES FINAIS}

No intuito de compreender narrativas de mulheres participantes da Feira Agroecológica e Cultural de Mulheres no Butantã, consubstanciado na estreita ligação percebida entre o movimento agroecológico e a economia solidária, na perspectiva da liderança feminina comunitária, esta pesquisa pretendeu evidenciar os processos experimentados e relatados nos microdocumentários da Série "Força Feminina: a Feira Agroecológica e Cultural de Mulheres no Butantã, produzida no ano de 2020.

Constatou-se que através da liderança feminina restou evidenciar a necessária construção de espaço coletivo eminentemente feminista, o qual acolhe, agrega, integra e fortalece o engajamento da mulher, como sujeito ativo, capaz de ensinar, aprender e decidir, dentro de uma dinâmica horizontal de atribuições, sendo, portanto, mais democrática, mais equitativa, diferenciando-se do modelo, tradicionalmente, dominante na nossa sociedade, no qual o homem é considerado líder natural, a partir dessa condição de gênero e da estrutura hierárquica pré-estabelecida.

Oportunizado esse espaço de diálogo e de participação feminina, enfatizou-se os ideais de sustentabilidade, associando a produção agroecológica com o movimento de economia solidária, o qual tem possibilitado a construção de ambiente profícuo à geração de renda, interligando os projetos de vida e de trabalho, sem desconsiderar a preocupação com o meio ambiente, vislumbrando uma relação integrada entre o ser humano e a natureza. Ademais, destacou-se o processo formativo e educativo como condição essencial à transformação social, em busca da redistribuição mais igualitária de afazeres do lar e dos cuidados familiares e de reprodução da vida, os quais devem ser, conscientemente, compartilhados, em prol do convívio familiar equilibrado, mais justo e harmônico.

Enfatizou-se, ainda, a preocupação com o respeito, com o resgate e a valorização dos saberes e princípios históricos e culturais ancestrais, como importante etapa do 
autoconhecimento e do fortalecimento da autoestima, compreendidos como elementos indispensáveis ao empoderamento feminino, propulsores do protagonismo e da liderança feminina pretendidos. Compreendeu-se, portanto, que a invisibilidade e a desvalorização das atividades "da mulher", combinada com a predominante desigualdade de gênero nas relações sociais, familiares e de trabalho, ainda se apresentam como grande obstáculo a ser vencido.

Atingidos os objetivos pretendidos com esta pesquisa, sugere-se a continuidade dos estudos que envolvem esta temática, de forma a ampliar, aprofundar e identificar novos aspectos relevantes, contribuindo para a construção de uma sociedade menos segregadora, mais justa e mais democrática.

\section{REFERÊNCIAS}

Agricultores familiares do Piauí aderem à venda por meios digitais. (fevereiro de 2021). Piauí Negócios. Disponível em < https://www.pinegocios.com.br/noticia/563Agricultores-familiares-do-Piaui-aderem-a-venda-por-meios-digitais $>$ Acesso em: 04 Jul. 2021.

ALMEIDA, R. A. Reforma agrária, mulheres e Agroecologia: construindo o consumo consciente em Três Lagoas-MS. Cadernos de Agroecologia, v. 15, n. 2. 2020.

ALTIERI, M. Agroecologia: bases científicas para uma agricultura sustentável. Agropecuária; AS-PTA. 2002.

Alves, C. B. C. \& Silva, M. R. C. Educação, cidadania e desenvolvimento sustentável-o programa mulheres mil no enfrentamento à feminização da pobreza. Caderno Espaço Feminino, v. 28, n. 1. 2015.

ALVES, J. N. et. al. A economia solidária no centro das discussões: um trabalho bibliométrico de estudos brasileiros. Cadernos EBAPE.BR, Rio de Janeiro, v. 14, n. 2, Paper 1, Abr./Jun. 2016a.

ALVES, N. F. et al. Ressignificação dos papéis sociais de mulheres na agricultura familiar de base agroecológica. Dissertação (mestrado) - Universidade Federal de Santa Catarina, Centro de Ciências Agrárias, Programa de Pós-Graduação em Agroecossistemas, Florianópolis. 2016b.

ANDRIOLI, A. Cooperativismo: uma resistência à exclusão. Revista espaço acadêmico, v. 2, n. 19. 2002.

ASSEBURG, H. B.; GAIGER, L. I. A economia solidária diante das desigualdades. Dados, 50, p. 499-533. 2007.

BARDIN, L. Análise de conteúdo. São Paulo: Edições 70. 2016. 
BEZERRA, A. G. C, et al. Mulheres, gênero e agroecologia na feira de agricultura familiar de São José de Mipibu. Revista Cadernos de Ciências Sociais da UFRPE, v. 2, n. 15 , p. 66-97. 2019.

BEZERRA, E. M. Trabalho de mulher, trabalho de homem no polo de confecções do agreste de Pernambuco. Tese (Doutorado em Ciências Sociais). Programa de Pós Graduação em Ciências Sociais da Universidade Estadual de Campinas. Instituto de Filosofia e Ciências Humanas. 2018.

BIROLI, F. Gênero e desigualdades: limites da democracia no Brasil. São Paulo, Boitempo. 2018.

BONA, C. De; MAY, Y. de O. Políticas públicas, economia solidária e a interface com gênero: uma alternativa para a autonomia econômica da mulher. Seminário Internacional Demandas Sociais e Políticas Públicas na Sociedade Contemporânea. 2019.

BRANDENBURG, A. Movimento agroecológico: trajetória, contradições e perspectivas. Desenvolvimento e meio ambiente, V. 6. 2002

BRASIL. Resolução/CD/FNDE/MEC $n^{\circ} 4$, de 3 de abril de 2015. Altera a redação dos artigos 25 a 32 da Resolução/CD/FNDE n 26, de 17 de junho de 2013, no âmbito do Programa Nacional de Alimentação Escolar (PNAE). 2015.

BRASIL. Lei Complementar $n^{o} 123$, de 14 de dezembro de 2006. Institui o Estatuto Nacional da Microempresa e da Empresa de Pequeno Porte. 2006.

BRASIL. Federal, Senado et al. Constituição da república federativa do Brasil, 1988.

Brumer, A. (2002). Previdência social rural e gênero. Sociologias, 50-81.

CAPORAL, F. R.; AZEVEDO, E. O. de (Org.) Princípios e perspectivas da agroecologia. Instituto Federal de Educação, Ciência e Tecnologia do ParanáEducação à Distância. 2011.

CAPORAL, F. R.; COSTABEBER, J. A. Agroecologia e extensão rural: contribuições para a promoção do desenvolvimento rural sustentável. Brasília: MDA/SAF/DATERIICA. 2004.

CAPORAL, F. R.; COSTABEBER, J. A. Análise multidimensional da sustentabilidade. Agroecología e desenvolvimento rural sustentavél, v. 3, n. 3, p. 70-85, 2002.

CASTRO, M. G. Feminização da pobreza em cenário neoliberal. Mulher e trabalho, v. $1,2001$.

CATTANI, A. D. Desigualdades socioeconômicas: conceitos e problemas de pesquisa. Sociologias, v. 8, p. 74-99. 2007.

CENSO Agro 2017, 2017. Instituto Brasileiro de Geografia e Estatística - IBGE. Disponível em < https://censos.ibge.gov.br/agro/2017/> Acesso em: 04 Jul. 2021. 
Coordenação Geral de Comunicação Social; Ministério da Agricultura, Pecuária e Abastecimento-MAPA; BRITO, Débora. Em 7 anos, triplica o número de produtores orgânicos cadastrados no Ministério da Agricultura. Disponível em: http://www.agroecologia.gov.br/noticia/em-7-anos-triplica-o-n\%C3\%BAmero-deprodutores-org\%C3\%A2nicos-cadastrados-no-minist\%C3\%A9rio-da-agricultura. Acesso em: 03 Jul. 2021.

CORTIZO, M. D. C.; OLIVEIRA, A. L. de. A economia solidária como espaço de politização. Serviço Social e Sociedade, v. 25, n. 80, p. 82-93. 2004.

COSTA, J. S. de M. et al. A face feminina da pobreza: sobre representação e feminização da pobreza no Brasil. (Texto para discussão - Instituto de Pesquisa Econômica Aplicada - IPEA). 2005.

DA SILVA, M. G., COSTA, B.; TEIXEIRA, R. Agroecologia e economia solidária: rede comunitária e canais curtos de comercialização. Cadernos de Agroecologia, v. 15, n. 2. 2020.

DAVI, A. C. C., et al. Promoção de produtos agroecológicos: espaço para trocas e saberes sobre sustentabilidade e consumo consciente. Cadernos de Agroecologia, v. 15 n. 2. 2020.

DOWBOR, L. Educação e desenvolvimento local. 2006. Disponível em: <www.dowbor.org> Acesso em: 28 Jun. 2021.

DUBEUX, A.; BATISTA, M. P. Agroecologia e economia solidária: um diálogo necessário à consolidação do direito à soberania e segurança alimentar e nutricional. Revista do Desenvolvimento Regional (REDES), v. 22, n. 2, p. 227-249. 2017.

EAGLY, A. H. Female leadership advantage and disadvantage: Resolving the contradictions. Psychology of women quarterly, v. 31, n. 1, p. 1-12. 2007.

EAGLY, A.; CARLI, L. Women and the labyrinth of leadership. Harvard Business Review, v. 85, n. 9, p. 62-71. 2007.

Economia solidária movimenta cerca de $\mathrm{R} \$ 12$ bilhões ao ano no Brasil. (julho de 2019). Economia. RBA - Rede Brasil Atual. Disponível em: $<$ https://www.redebrasilatual.com.br/economia/2019/07/economia-solidariamovimenta-cerca-de-r-12-bilhoes-ao-ano/>Acesso em: 04 Jul. 2021.

ESTEVAM, D. O., et al. Cooperativas descentralizadas (ou virtuais): (Re) conectando pessoas, produtos e o lugar em cadeias curtas de produção e comercialização. Anais dos Encontros Nacionais de Engenharia e Desenvolvimento Social, v. 10, n. 1, p. 18-18. 2013.

Feira Agroecológica e Cultura de Mulheres no Butantã, 2021. Disponível em: $<$ https://feiramulheresagroecologica.com.br> Acesso em: 27 Set. 2021. 
FONSECA, A. M. de O.; PORTO, J. B.; BORGES-ANDRADE, J. E. Liderança: um retrato da produção científica brasileira. Revista de Administração Contemporânea, v. 19, p. 290-310. 2015.

FRIEDMANN, J., et. al. Empowerment: uma política de desenvolvimento alternativo. Oeiras: Celta Editora. 1996.

GAIGER, L. I. O Mapeamento Nacional e o conhecimento da Economia Solidária. Brazilian Journal of Labour Studies - Revista da ABET, v. 12, n. 1. 2013.

GIL, A. C. Como elaborar projetos de pesquisa. São Paulo: Editora Atlas SA. 2008

GOMEZ, M.; DE LUCENA, E. A. R. M.; CRISTINA, A. Emponderamento da mulher através de feiras agroecológicas na cidade de Ilhéus, Bahia/Brasil. Forum Sociológico, v. 2 n. 29 , p. 65-76. 2016.

GRIMM, S.; OLIVEIRA, E. D. Autonomia feminina no meio rural: o estudo da cooperativa de mulheres de São Ludgero/SC. Seminário de Ciências Sociais Aplicadas, v. 6, n. 6. 2018.

GUÉRIN, I. Sociologia Econômica e relações de gênero. In: M. Emílio (org.). Trabalho e cidadania ativa para as mulheres: desafios para as políticas públicas. São Paulo, Prefeitura Municipal Coordenadoria Especial da Mulher. 2003.

GUÉRIN, I. Mulheres e a economia solidária. São Paulo: Edições Loyola. 2005.

HRYNIEWICZ, L. G. C.; VIANNA, M. A. Mulheres em posição de liderança: obstáculos e expectativas de gênero em cargos gerenciais. Cadernos EBAPE.BR, v. 16, p. 331-344. 2018.

JESUS CRUZ, J.; OLIVEIRA, L.; JOSÉ, R.; CAMPOS, L. K. C. Agricultura familiar: a feira agroecológica como base para o empoderamento feminino. Cadernos Macambira, v. 5, n. 2, p. 126-131. 2020.

LAGARDE, M. et. al. Género y feminismo: desarrollo humano y democracia. Siglo XXI Editores México. 2018.

LEAL, K. S.; SÁ RODRIGUES, M. de. Economia solidária: conceitos e princípios norteadores. Humanidades \& Inovação, v.5, n. 11, p. 209-219. 2018.

LEITE, D. C.; TELES, E. C. P. V. de A. Comercialização de produtos agroecológicos a partir de circuitos curtos: a experiência das feiras agroecológicas de Recife, Revista de Extensão da UNIVASF (EXTRAMUROS), v. 7, n. 2, p. 026-044. 2020.

LIMA, L. de O., et. al. Feiras livres como geração de renda para os agricultores/as familiares do município de Capitão Poço no nordeste paraense. Cadernos de Agroecologia, v. 13, n. 1. 2018.

MACEDO, M. dos S. Mulheres chefes de família e a perspectiva de gênero: trajetória de um tema e a crítica sobre a feminização da pobreza. Caderno $C R H$, v. 21, n. 53, p. 389-404. 2008. 
MACHADO, H. V, Identidade empreendedora de mulheres no Paraná. Tese (doutorado) - Universidade Federal de Santa Catarina, Centro Tecnológico. Programa de Pós-Graduação em Engenharia de Produção. 2002.

MONTEIRO, D.; LONDRES, F. Pra que a vida nos dê flor e frutos: notas sobre a trajetória do movimento agroecológico no Brasil. In.: SAMBUICHI et. al. (Org.). A política nacional de agroecologia e produção orgânica no Brasil: uma trajetória de luta pelo desenvolvimento rural sustentável - Brasília: Ipea. 2017.

MOREIRA, S. L. de S. A contribuição da Marcha das Margaridas na construção das políticas públicas de agroecologia no Brasil. Dissertação (Mestrado em Meio Ambiente e Desenvolvimento Rural) - Universidade de Brasília, Brasília. 2019.

MUÑOZ, P.; KIBLER, E. Institutional complexity and social entrepreneurship: A fuzzy-set approach. Journal of Business Research, v. 69, n. 4, p. 1314-1318. 2016.

NASCIMENTO SILVA, E. Gênero e comunidade: olhares sobre a liderança de mulheres em espaços comunitários. Revista Científica UMC, 2020, v. 5, n. 3. 2020.

NORDER, L. A.; LAMINE, C.; BELLON, S. BRANDENBURG. Agroecologia: polissemina, pluralismo e controvérsia. Ambiente \& Sociedade, v. 19, n. 3, p. 1-20. 2016.

NOVELLINO, M. S. F. Os estudos sobre feminização da pobreza e políticas públicas para mulheres. XIV Encontro Nacional de Estudos Populacionais, ABEP, p. 1-12. 2004.

OLIVEIRA, A. L. A trajetória de empoderamento de mulheres na economia solidária. Revista Gênero, v. 5, n. 2. 2005,

OLIVEIRA, A. L. M.; ABREU, S. A. Contribuições teóricas e práticas da economia feminista à economia solidária. Cadernos Latino-Americanos de Políticas e Sociedade (CODAS), v. 1, n. 1, p. 25-40. 2020.

OLIVEIRA, C. Mulheres lutam para preservar espaço de agroecologia e economia solidária. Cidadania, 2019. Disponível em: $<$ https://www.redebrasilatual.com.br/cidadania/2019/12/mulheres-agroecologia-eeconomia-solidaria/> Acesso em: 28 Jun. 2021.

ORGANIS. (n.d). Disponível em <https://organis.org.br/>Acesso em: 03 Jul. 2021.

O que é a ANA. Articulação Nacional de Agroecologia (s.d) (ANA). Disponível em $<$ https://agroecologia.org.br/o-que-e-a-ana/ZAcesso em: 28 Jul. 2021

SANTOS, A. M. Os dilemas da organização popular no movimento da economia solidária no Brasil. Otra Economía, v. 8, n. 15, p. 196-209. 2014.

SAMBUICHI, R. H. R. et. al. (Org.) A política nacional de agroecologia e produção orgânica no Brasil: uma trajetória de luta pelo desenvolvimento rural sustentável. Brasília: Ipea. 2017. 
Setor de orgânicos cresce 30\% no Brasil em 2020 (fevereiro de 2021). Associação Brasileira de Supermercados (ABRAS). Disponível em $<$ https://www.abras.com.br/clipping/geral/72392/setor-de-organicos-cresce-30-nobrasil-em-2020 >Acesso em: 03 Jul. 2021.

SILIPRANDI, E. Mulheres e agroecologia: transformando o campo, as florestas e as pessoas. Rio de Janeiro: Editora UFRJ. 2015.

SILIPRANDI, E. Um olhar ecofeminista sobre as lutas por sustentabilidade no mundo rural. In: Petersen, P. (Org). Agricultura familiar camponesa na construção do Futuro. Rio De Janeiro: AS-PTA, p. 139-151. 2009.

SILVA, J. F. G.; VELHO, O. G. A modernização dolorosa: estrutura agrária, fronteira agrícola e trabalhadores rurais no Brasil. Rio de Janeiro: Zahar Editores. 1981.

SILVA, S. P. O campo de pesquisa da economia solidária no Brasil: abordagens metodológicas e dimensões analíticas. Texto para discussão - Instituto de Pesquisa Econômica Aplicada.- Brasília: Rio de Janeiro: Ipea. 2018.

SINGER, P. Economia solidária. Estudos avançados, v. 22, n. 62, p. 289-314. 2008.

SINGER, P. A economia solidária como ato pedagógico. In.: KRUPPA (Org.) Economia solidária e educação de jovens e adultos. Brasília: Inep. 2005.

SINGER, P. A recente ressurreição da economia solidária no Brasil. In.: SANTOS B. de S. (Org.) Produzir para viver: os caminhos da produção não capitalista. Rio de Janeiro: Civilização Brasileira. 2002.

TAMES, D. Four approaches to structuring micro-documentaries. Kyno-Eye.com. 2014. Disponível em <https://kino-eye.com/2014/11/17/structuring-micro-docs/> Acesso em: 02 Set. 2021.

WEZEL, A. et al. Agroecology as a science, a movement and a practice. A review. Agronomy for sustainable development, v. 29, n. 4, p. 503-515. 2009.

WOITOWICZ, K. J. Reseña de As "mulheres ou os silêncios da história" de Michelle PERROT.Revista Estudos Feministas, v. 16, n. 1, p. 253-256. 2008. 